
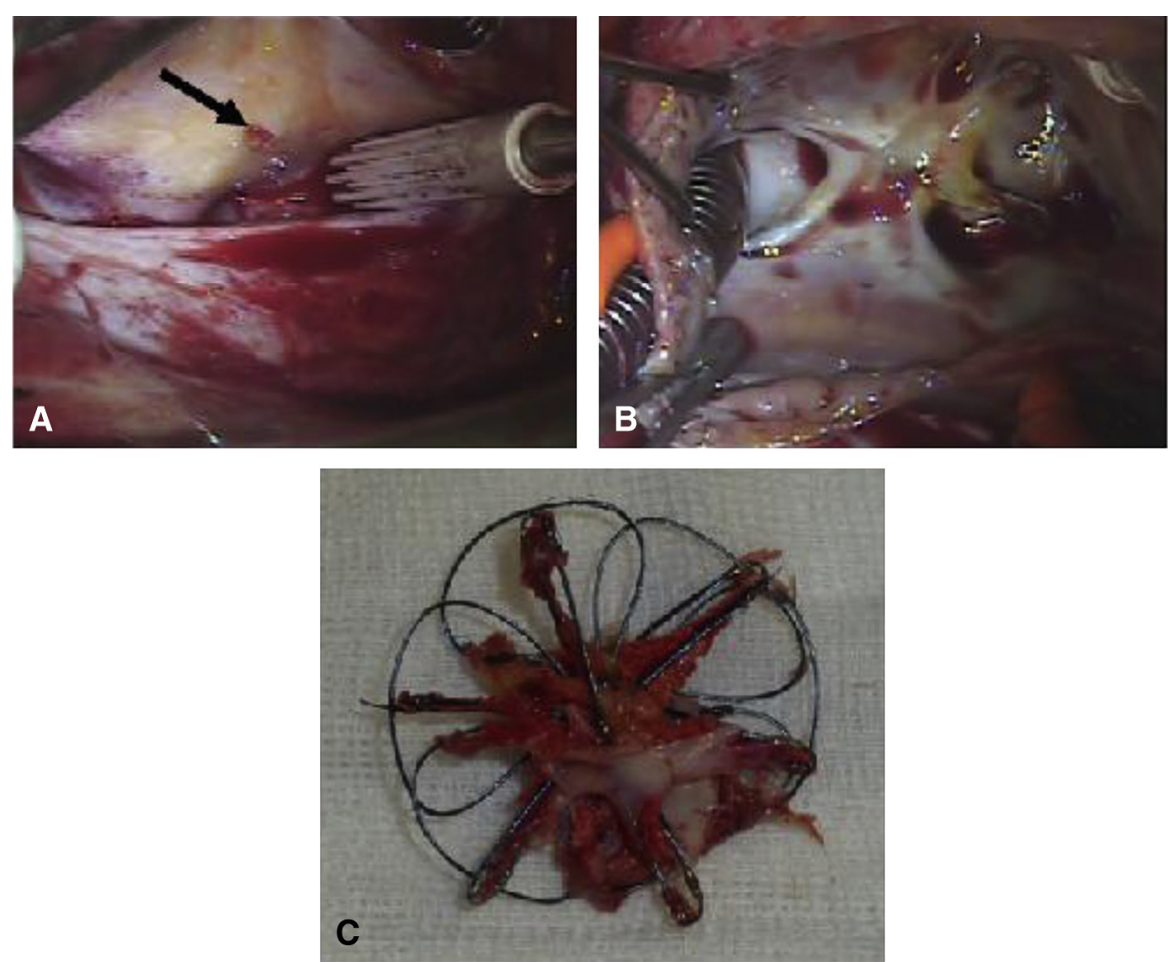

FIGURE 1. Operative findings. A, Intraoperative photograph shows perforation of the right atrium by an occluder strut (arrow). B, Intraoperative photograph shows atrial septal occluder in situ, before removal (visualized through the opened right atrium). $\mathrm{C}$, The removed device can be seen clearly in this photograph.

\section{References}

1. Berdat PA, Chatterjee T, Pfammatter JP, Windecker S, Meier B, Carrel T. Surgical management of complications after transcatheter closure of fore an atrial septal defect or patent foramen ovale. J Thorac Cardiovasc Surg. 2000;120:1034-9.

2. Brown S, Gewillig M. Perforation of the aortic sinus after closure of atrial septal defects with the Atriasept occluder. Catheter Cardiovasc Interv. 2009;74:298-301.

3. Sarris GE, Kirvassilis G, Zavaropoulos P, Belli E, Berggren H, Carrel T, et al. Surgery for complications of trans-catheter closure of atrial septal defects: a multi-institutional study from the European Congenital Heart Surgeons Association. Eur J Cardiothorac Surg. 2010;37:1285-90.

4. Chessa M, Carminati M, Butera G, Bini RM, Drago M, Rosti L, et al. Early and late complications associated with transcatheter occlusion of secundum atrial septal defect. J Am Coll Cardiol. 2002;39:1061-5.

5. Taggart NW, Dearani JA, Hagler DJ. Late erosion of an Amplatzer septal occluder device 6 years after placement. J Thorac Cardiovasc Surg. 2011;142: $221-2$.

\title{
Endobronchial ultrasonographically guided transbronchial needle aspiration in mediastinal abscesses
}

Yen-Fu Chen, MD, ${ }^{\mathrm{a}}$ Chao-Chi Ho, MD, PhD, ${ }^{\mathrm{b}}$ Chung-Yu Chen, MD, ${ }^{\mathrm{a}}$ and Chong-Jen Yu, MD, PhD, ${ }^{\mathrm{b}}$ Douliou City and Taipei, Taiwan

\footnotetext{
From the Department of Internal Medicine, ${ }^{\mathrm{a}}$ National Taiwan University Hospital, Yunlin Branch, Douliou City, Taiwan; and the Department of Internal Medicine, ${ }^{b}$ National Taiwan University Hospital, Taipei, Taiwan.

Disclosures: Authors have nothing to disclose with regard to commercial support.

Received for publication Oct 6, 2012; revisions received Jan 16, 2013; accepted for publication Feb 12, 2013; available ahead of print March 7, 2013.

Address for reprints: Chung-Yu Chen, MD, No. 579, Section 2, Yunlin Rd, Douliou City, Yunlin County 640, Taiwan (E-mail: c8101147@ms16.hinet.net).

J Thorac Cardiovasc Surg 2013;145:e54-7

0022-5223/\$36.00

Copyright (C) 2013 by The American Association for Thoracic Surgery

http://dx.doi.org/10.1016/j.jtcvs.2013.02.025
}

Mediastinal abscess is a serious condition carrying a high mortality and requiring surgical intervention. Real-time endobronchial ultrasonographically guided transbronchial needle aspiration (EBUS-TBNA), which is used for obtaining mediastinal tissue samples, is a safer and less invasive method than surgery. ${ }^{1}$ Here we present 2 cases of patients with mediastinal abscess diagnosed by EBUS-TBNA and discuss the related issues. 


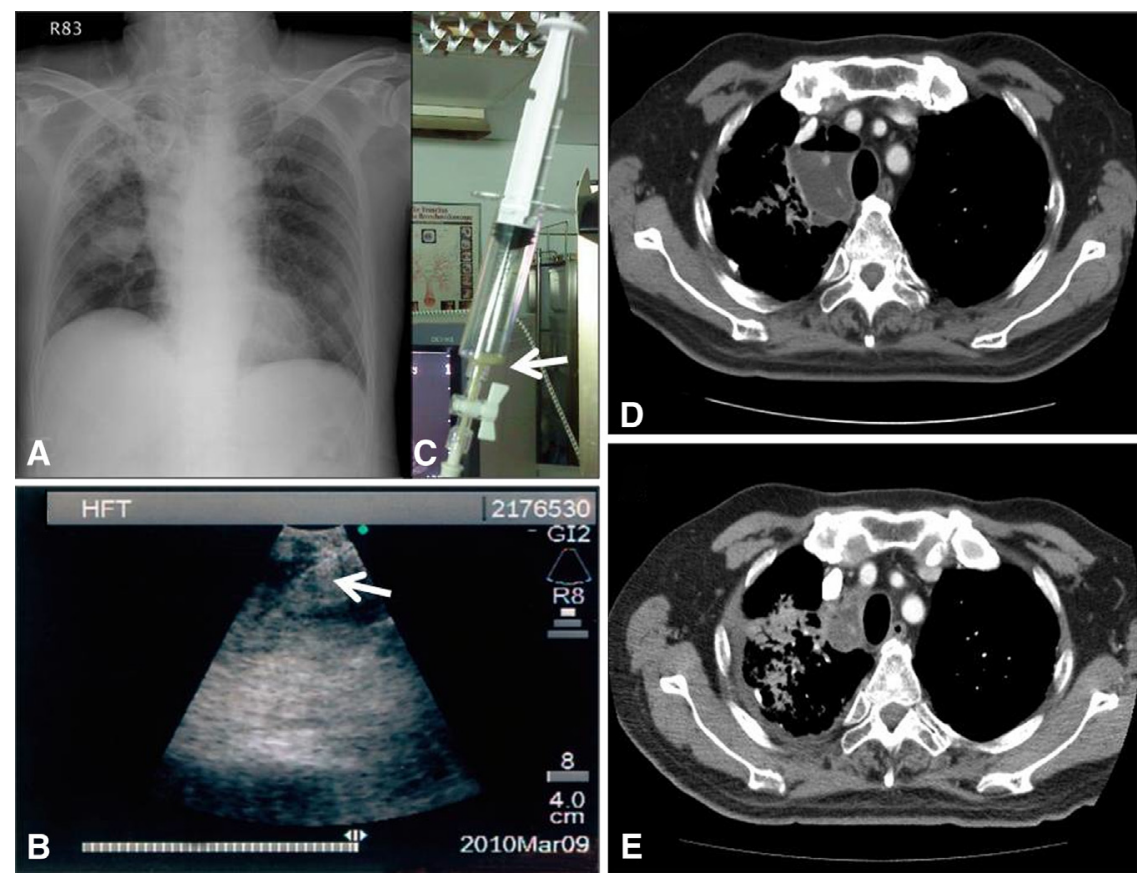

FIGURE 1. Patient 1. A, Chest radiographic image showing a new lesion over the right upper lung lobe. B, Ultrasonographic image showing the 22-gauge needle (white arrow) of the endobronchial ultrasonographically guided transbronchial needle aspiration puncturing the fluid-filled mediastinal abscess. C, The aspiration vacuum syringe containing yellowish cloudy pus (white arrow) from the mediastinal abscess. D, Chest computed tomographic image showing a heterogeneous, hypodense lesion (diameter $5.8 \mathrm{~cm}$ ) with an air-fluid level. E, Chest computed tomographic image after 1 month of treatment with antibiotics shows reduction in the size of the mediastinal abscess. The lesion in the left upper lobe of the lung, however, shows disease progression.

\section{CLINICAL SUMMARIES Patient 1}

A 67-year-old man was admitted for lung adenocarcinoma with brain metastasis. During his hospitalization, fever and dyspnea developed. A chest radiograph revealed a new lesion overlying the right upper lobe of the lung (Figure 1, A). Chest computed tomography (CT) showed a heterogeneous and hypodense lesion with an air-fluid level in the right paratracheal region (Figure 1,D). Surgical intervention was contraindicated by the patient's poor overall condition. EBUS-TBNA was therefore performed with the patient under conscious sedation. We identified a heterogeneous, hypoechoic, cystic lesion in the right paratracheal area by using EBUS-TBNA with a convex ultrasound transducer. Under real-time endobronchial ultrasonographic guidance, a 22-gauge needle was inserted into the lesion (Figure 1, B); the stylet was then removed, and an aspiration vacuum syringe with a 3 -way tap was used to apply negative pressure to the aspiration needle. Yellowish, cloudy pus $(10 \mathrm{~mL})$ was then aspirated into a vacuum syringe (Figure 1,C). We completed the procedure in approximately 30 minutes, and the patient tolerated the procedure well. Rapid on-site cytopathologic examination showed numerous pus cells and gram-negative bacilli without malignant cells. Subsequent pus cultures yielded Klebsiella pneumoniae. The patent received a 6-week course of appropriate antibiotics on the basis of antimicrobial sensitivity test results. The fever and dyspnea gradually subsided, and the size of the lesion decreased (Figure 1,E) 1 month later.

\section{Patient 2}

A 63-year-old woman was seen for a month-long history of productive cough and progressive dyspnea. Her chest CT scan revealed a large subcarinal cystlike lesion (Figure 2, A). The EBUS-TBNA procedure was applied to determine the etiology, and the endobronchial ultrasonographic image showed a heterogeneous, hypoechoic, cystic lesion over the subcarinal region (Figure 2, C). Under real-time endobronchial ultrasonographic guidance, a 22-gauge needle was punctured into the lesion (Figure 2,D, white arrow), and small amount of yellowish turbid fluid was aspirated from the lesion with the aspiration vacuum syringe. A rapid on-site cytopathologic examination showed many inflammatory cells and necrotic materials but no malignant cells. Acid-fast bacilli were detected, and the diagnosis was finally confirmed by the detection of Mycobacterium tuberculosis in the pus culture. After 6 months of antituberculosis medication therapy, a follow-up chest CT showed a reduction in the size of the mediastinal lesion (Figure 2,B). 


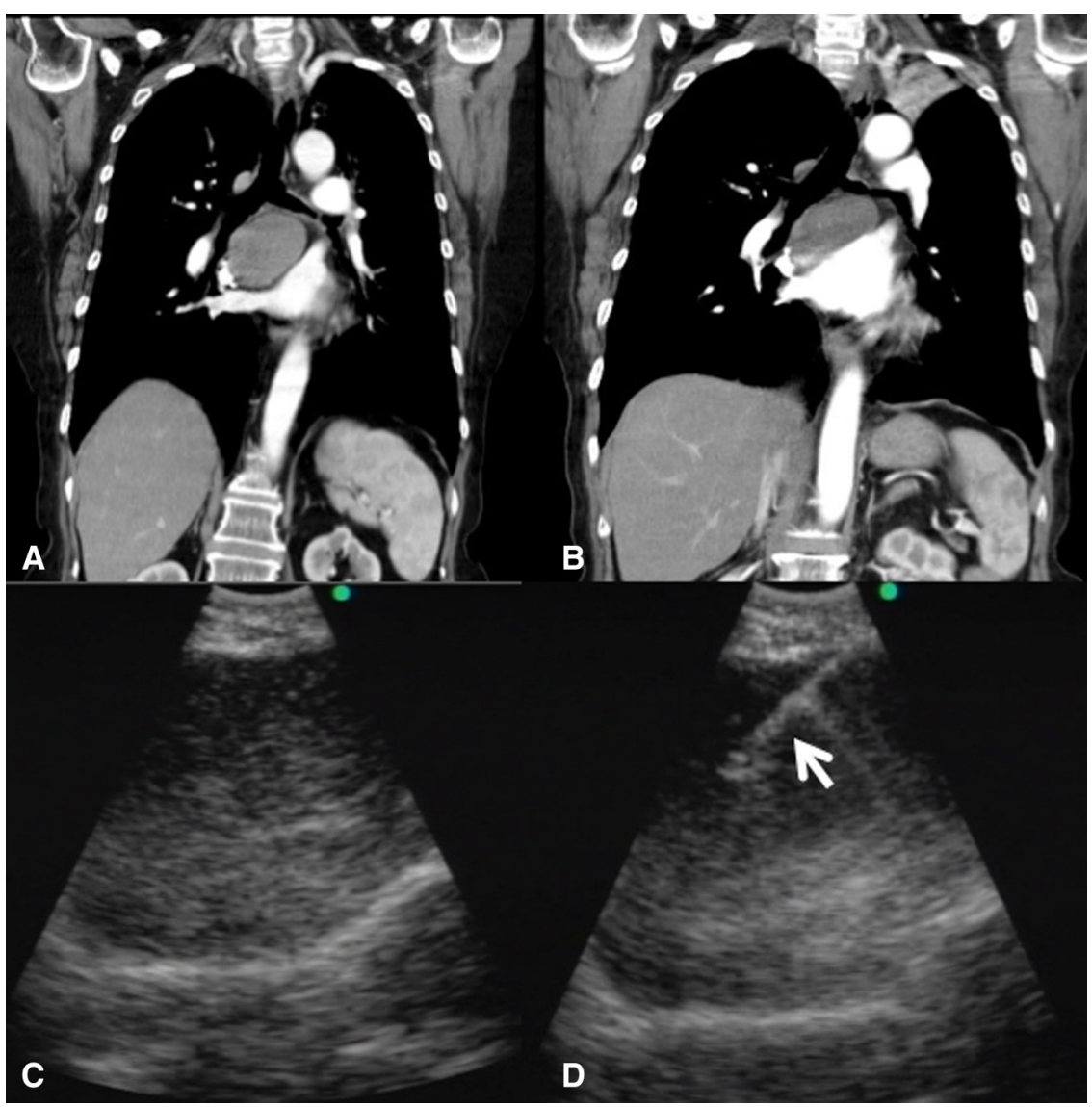

FIGURE 2. Patient 2. A, Chest computed tomographic image showing a large mass (diameter $5.3 \mathrm{~cm}$ ) in the subcarinal area and posterior mediastinum, causing left atrial compression. B, Chest computed tomographic image obtained after 6 months of antituberculosis treatment showing regression in the mass (diameter $4.6 \mathrm{~cm}$ ) at the subcarinal area and posterior mediastinum. C and D, The endobronchial ultrasonographically guided transbronchial needle aspiration image showing a large heterogeneous, hypoechoic cystic lesion over the subcarinal region and the 22-gauge needle (white arrow) puncturing into the subcarinal lesion with tissue aspiration.

\section{DISCUSSION}

Early and accurate identification of the mediastinal pathogen, complete surgical resection, and adjuvant systemic antibiotic therapy are recommended for the management of mediastinal abscesses ${ }^{2}$; however, surgery and general anesthesia pose a high risk in patients with a poor health status. CT-guided percutaneous drainage has been proposed as an effective alternative to surgery, but it may involve a high risk of serious mediastinal complications and excessive exposure to radiation. ${ }^{3}$ There are a few published reports on the application of EBUS-TBNA in the diagnosis and partial treatment of mediastinal cysts ${ }^{4,5}$; however, this diagnostic modality has not previously been used in interventions for mediastinal abscesses.

In our 2 cases, the EBUS-TBNA system equipped with a convex probe enabling color Doppler study helped to locate and characterize the mediastinal abscess and to distinguish it clearly from adjacent vascular structures. In addition, the system provides real-time visualization when the aspiration needle is advanced through the bronchial wall into the target lesion, thereby guaranteeing precision in approaching the lesion site. We used a 22-gauge needle for aspiration and inserted it at the target abscess site; the abscess tissue was collected by slowly moving the needle back and forth inside the lesion. Because a negative pressure was created by using an aspiration vacuum syringe, the dense, heterogeneous contents of the abscess could be drained through the working channel of a flexible bronchoscope, thereby increasing the amount of specimen obtained for microbiologic analysis.

Moreover, the EBUS-TBNA system may allow better access to infectious mediastinal regions than CT-guided procedures or mediastinoscopy, and it also is less invasive with a shorter procedure time. This technique requires only mild sedation and local anesthesia for 30 minutes when performed by experienced bronchoscopists. The potential complication (bleeding) associated with the EBUS-TBNA system seldom occur under real-time visualization of the needle. Even if the vascular structure is punctured, it is usually inconsequential once the needle is 
removed $^{1}$; however, the contaminated needle puncture may be associated with subsequent mediastinal infection, so empirical antimicrobial therapy is suggested in selected cases. ${ }^{6}$

In conclusion, surgeons could consider EBUS-TBNA as an effective and alternative option in the diagnosis, subsequent surgical intervention, and identification of the causative agent of mediastinal infections in patients who are unable to undergo surgery.

\section{References}

1. Medford AR, Bennett JA, Free CM, Agrawal S. Endobronchial ultrasound-guided transbronchial needle aspiration (EBUS-TBNA): applications in chest disease. Respirology. 2010;15:71-9.
2. Yokote K, Osada H, Tsukada H, Kurisu S, Taira Y, Yamate N. Treatment of mediastinal abscess. Nippon Kokyu Geka Gakkai Zasshi. 1998;12:74-9.

3. Tanaka T, Inaba Y, Arai Y, Matsueda K, Aramaki T, Dendo S. Mediastinal abscess successfully treated by percutaneous drainage using a unified CT and fluoroscopy system. Br J Radiol. 2002;75:470-3.

4. Nakajima T, Yasufuku K, Shibuya K, Fujisawa T. Endobronchial ultrasoundguided transbronchial needle aspiration for the treatment of central airway stenosis caused by a mediastinal cyst. Eur J Cardiothorac Surg. 2007;32: 538-40.

5. Meseguer SM, Franco SJ. [Drainage of a mediastinal cyst by endobronchial ultrasound-guided needle aspiration]. Arch Bronconeumol. 2010;46:206-12. Spanish.

6. Huang CT, Chen CY, Ho CC, Yu CJ. A rare constellation of empyema, lung abscess, and mediastinal abscess as a complication of endobronchial ultrasound-guided transbronchial needle aspiration. Eur J Cardiothorac Surg. 2011;40:264-5.

\title{
Dissected axillary artery cannulation in redo-total arch replacement surgery
}

\author{
Prashanth Vallabhajosyula, MD, R. Scott McClure, MD, C. William Hanson III, MD, and \\ Y. Joseph Woo, MD, Philadelphia, Pa
}

Despite the increased use of axillary artery cannulation in aortic surgery, extension of an aortic dissection into the axillary artery remains a relative contraindication to its use. Deleterious effects associated with false lumen cannulation are of real concern and particular consequence with the axillary artery. Blood flow into the false lumen at this level risks cerebral malperfusion because of the proximity of the cerebral vessels. We describe a case of successful transesophageal echocardiography-guided true lumen cannulation of a dissected axillary artery in the face of accompanying distal dissection into the femoral vessels during complex redo aortic arch surgery.

Axillary artery cannulation has become the preferred strategy for many surgeons when reconstructing the ascending aorta or the aortic arch. ${ }^{1}$ Key benefits to axillary artery cannulation include the ability to maintain antegrade systemic blood flow during cardiopulmonary bypass, as well as enabling selective antegrade cerebral

\footnotetext{
From the Division of Cardiovascular Surgery, Department of Surgery, University of Pennsylvania School of Medicine, Hospital of the University of Pennsylvania, Philadelphia, Pa.

Disclosures: Authors have nothing to disclose with regard to commercial support.

Received for publication Nov 10, 2012; accepted for publication Feb 12, 2013; available ahead of print March 13, 2013.

Address for reprints: Y. Joseph Woo, MD, Division of Cardiovascular Surgery,

Department of Surgery, 3400 Spruce St, 6 Silverstein, Philadelphia, PA 19104

(E-mail: wooy@uphs.upenn.edu).

J Thorac Cardiovasc Surg 2013;145:e57-9

0022-5223/\$36.00

Copyright (c) 2013 by The American Association for Thoracic Surgery

http://dx.doi.org/10.1016/j.jtcvs.2013.02.020
}

perfusion via positioning of a clamp onto the proximal innominate artery. ${ }^{1}$ Although contraindications to this technique are few, an aortic dissection that extends into the axillary artery is a perceived relative contraindication to its use. ${ }^{2}$ Typically, the lumen of an arterial dissection is predominantly that of the false lumen, with the true lumen relegated to less than $50 \%$ of the original diameter. With the smaller diameter of the axillary artery, access to the true lumen in the face of a dissection can be rather challenging. Undetected cannulation of the false lumen with the establishment of cardiopulmonary bypass has the potential to be catastrophic, causing severe cerebral malperfusion. Still, in situations in which alternative arterial access is prohibitive, true lumen cannulation of a dissected vessel can be an invaluable technique. We report a case of successful transesophageal echocardiography-guided true lumen cannulation of a dissected axillary artery in a patient with chronic aneurysmal dissection of the aortic arch and descending thoracic aorta several years after a previous ascending aortic repair for a DeBakey type I aortic dissection. ${ }^{3}$

\section{CLINICAL SUMMARY}

A 60-year-old African American man with a medical history of poorly controlled essential hypertension, 12 years after ascending aorta and hemiarch repair of a DeBakey type I aortic dissection in conjunction with an aortic valve resuspension, presented to the hospital with shortness of breath. Cardiac workup revealed new-onset atrial fibrillation, severe aortic insufficiency with aortic root dilatation, 